\title{
Cytokine response in patients with chronic infections caused by Staphylococcus aureus strains and diversification of their Agr system classes
}

\author{
A. Szkaradkiewicz • T. M. Karpiński - A. Zeidler • \\ A. K. Szkaradkiewicz • H. Masiuk • S. Giedrys-Kalemba
}

Received: 15 March 2012 / Accepted: 20 April 2012 /Published online: 26 May 2012

(C) The Author(s) 2012. This article is published with open access at Springerlink.com

\begin{abstract}
This study aimed to describe the levels of circulating cytokine levels produced by Th lymphocytes (IFN- $\gamma$, IL4 , IL-10, IL-17A), as well as the levels of cytokines produced by monocytes/macrophages (TNF- $\alpha$, IL- $1 \beta$, IL-12), in patients with chronic infections caused by Staphylococcus aureus strains, particularly in the context of the diversification of their Agr system classes. The studies were conducted on adult patients, including 50 patients with chronic suppurative dermatitis, 40 patients with chronic infections of the upper respiratory tract and 25 healthy individuals (control group). Blood serum cytokine levels were measured by enzymelinked immunosorbent assay (ELISA). S. aureus was detected in cultures of suppurative dermal exudates or of pharyngeal smears. Classes of Agr systems in the $S$. aureus strains were identified using polymerase chain reaction (PCR). In both groups of patients, on average, levels of IFN $-\gamma$ were doubled, while levels of IL-17A were increased by 2.5 -fold, which, however, was not accompanied by increased levels of TNF$\alpha$ or IL-12. The data indicate that the development of $S$. aureus infection among the studied patients was linked to an impoverished cytokine response of monocytes/macrophages,
\end{abstract}

\author{
A. Szkaradkiewicz $(\bowtie) \cdot$ T. M. Karpiński $\cdot$ A. Zeidler \\ Department of Medical Microbiology, \\ University of Medical Sciences in Poznań, \\ Wieniawskiego 3, Str., \\ 61-712 Poznań, Poland \\ e-mail: szkaradkiewicza@poczta.onet.pl

\section{A. K. Szkaradkiewicz} \\ Department of Conservative Dentistry and Periodontology, \\ University of Medical Sciences in Poznań, \\ Poznań, Poland \\ H. Masiuk $\cdot$ S. Giedrys-Kalemba \\ Department of Microbiology and Immunology, \\ Pomeranian Medical University, \\ Szczecin, Poland
}

while that induced by the pathogen lymphocytes Th17/Th1 may be responsible for promotion of the chronic inflammatory response. In parallel, no quantitative or qualitative differences were disclosed between cytokine responses manifested by subgroups of patients infected with $S$. aureus strains belonging to class IV Agr, as compared to patients infected with strains of classes I to III Agr. Nevertheless, in the patients, strains belonging to class IV Agr prevailed, which points to the preferential relationship between the class and the pathogenicity of $S$. aureus.

\section{Introduction}

The propensity of humans to develop community-acquired chronic infections with Staphylococcus aureus is well known and is most frequently manifested by chronic suppurative dermatitis or chronic infection in the upper respiratory tract. Therapy of such conditions with antibiotics used to be ineffective and linked to a persisting infection with $S$. aureus [1-4]. The role of immune reactions in the pathogenesis of chronic $S$. aureus infections still remains unclear. In the immune reaction, a very significant role is played by the cytokine response of lymphocytes Th and of monocytes/macrophages [5]. In turn, the pathogenicity of $S$. aureus is determined by the production of several virulence factors, in the pathogen remaining under the control of the global regulatory system Agr (accessory gene regulator), encoded by the agr locus [6-9]. Polymorphism of the agr locus allows to distinguish four major different classes of Agr system, referred to as AgrI, Agr-II, Agr-III and Agr-IV. In parallel, their relationship is examined in relation to the type of human disease caused by $S$. aureus [10-12]. Considering the above, this study aimed to evaluate the circulating cytokine levels, mainly those produced by subpopulations of lymphocytes $\mathrm{T}$ helper (Th): 
interferon (IFN)- $\gamma$, interleukin (IL)-4, IL-10 and IL-17A, as well as of cytokines, mainly those produced by monocytes/ macrophages: tumour necrosis factor (TNF)- $\alpha$, IL- $1 \beta$ and IL12 , in patients with chronic staphylococcal infection in the context of diversification between Agr classes among the clinically isolated strains of $S$. aureus.

\section{Materials and methods}

\section{Patients}

The studies were performed in the Department of Medical Microbiology, University of Medical Sciences in Poznan and in the Department of Microbiology and Immunology, Pomeranian Medical University in Szczecin, Poland, over a period of two years (2010-2011). All the research protocols were reviewed and approved by the Ethics Committee at the University of Medical Sciences in Poznań, Poland.

A total of 90 adult patients with chronic suppurative dermatitis or chronic infection in the upper respiratory tract induced by $S$. aureus (referred by dermatologists and otolaryngologists) were recruited into the study. Additionally, 25 healthy individuals without bacteriological evidence of $S$. aureus infection served as a control group. Taking into account clinical data and the results of bacteriological tests, three study groups were distinguished. Group 1 included 50 patients (28 men, 22 women, age range: $18-52$, mean: $35.3 \pm 9.2$ years) with exacerbation or a relapse of chronic suppurative dermatitis, manifested at least within the previous 6 months before inclusion into the study by chronic folliculitis or a relapsing furunculosis with isolation from the suppurative dermal exudate of $S$. aureus. Group 2 included 40 patients (18 men, 22 women, age range: 18-52, mean: $36.4 \pm 9.4$ years) with exacerbation of chronic infection in the upper respiratory tract, manifested at least within the previous 6 months before inclusion to the studies of chronic rhinopharyngitis or chronic pharyngitis, in the throat smears of whom the presence of $S$. aureus was disclosed. Group 3 (control) included 25 patients (11 men, 14 women, age range: 18-50, mean: $33.6 \pm$ 9.4 years) in whom bacteriological examination of nasal and pharyngeal smears failed to demonstrate the presence of $S$. aureus. Moreover, dental examinations of patients failed to find any potential infection foci in the oral cavity. Within the previous 2 weeks, none of the patients in the mentioned groups were administered with antibiotics/chemotherapeutic agents locally or systemically. The material for studies involved nasal and pharyngeal smears, exudate from suppurative skin lesions and samples of peripheral blood.

\section{S. aureus detection}

The bacteria were isolated on sheep blood agar within 20 $24 \mathrm{~h}$ at a temperature of $37^{\circ} \mathrm{C}$ in aerobic conditions. The developed colonies were subsequently identified as coagulase-positive staphylococci using conventional techniques (colony morphology, evaluation of haemolysis, staining according to Gram, production of coagulase, catalase, ability to decompose mannitol in Chapman medium). Final identification of $S$. aureus was conducted using the automated system ATB with the application of ID 32 Staph strips (bioMérieux). In the examined materials, the presence of no other pathogens was disclosed.

\section{Purification of DNA}

DNA was isolated from the obtained isolates of $S$. aureus clinical strains. At first, the samples were digested with lysostaphin $(10 \mu \mathrm{l}$ of $1 \mathrm{mg} / \mathrm{ml}$ solution) and incubating them for $10 \mathrm{~min}$ at a temperature of $37^{\circ} \mathrm{C}$. Subsequently, $20 \mu \mathrm{l}$ of proteinase $\mathrm{K}$ was added to each sample and, following mixing, the samples were incubated for $20 \mathrm{~min}$ at a temperature of $37^{\circ} \mathrm{C}$.

For the isolation of DNA, Sherlock AX (A\&A Biotechnology, Gdynia, Poland) kits were used. The isolation of DNA was conducted as recommended by the manufacturer. The purified DNA was stored at $-20{ }^{\circ} \mathrm{C}$ until further analyses were performed.

\section{Detection of Agr classes}

The Agr classes were determined by two duplexes of polymerase chain reaction (PCR) according to the method of Shopsin et al. [11]. Since the PCR product sizes of Agr classes I and III and classes II and IV were similar, two duplex PCR reactions were performed. The reverse primers I (product size: $440 \mathrm{bp}$ ) and IV (product size: $588 \mathrm{bp}$ ) were used in the first reaction, and primers II (product size: $572 \mathrm{bp}$ ) and III (product size: $406 \mathrm{bp}$ ) were used in the second reaction.

PCR was performed in the Mastercycler gradient thermal cycler (Eppendorf). Aliquots of amplified samples $(10 \mu \mathrm{L})$ were analysed by electrophoresis on a $1 \%$ agarose gel and stained with ethidium bromide.

\section{Determination of cytokines}

Cytokines were estimated in patient sera using an immunoenzymatic technique (enzyme-linked immunosorbent assay, ELISA). The tests took advantage of the following kits: for IFN- $\gamma$ : Human IFN- $\gamma$ High Sensitivity ELISA kit (eBioscience), manifesting a minimum detection dose (MDD) of $0.06 \mathrm{pg} / \mathrm{ml}$; for IL-4: Quantikine HS Human IL-4 Immunoassay kit (R\&D Systems), manifesting an MDD of $0.11 \mathrm{pg} /$ 
ml; for IL-10: Quantikine HS Human IL-10 Immunoassay kit (R\&D Systems), manifesting an MDD of $0.5 \mathrm{pg} / \mathrm{ml}$; for IL-17A: Platinum Human IL-17 ELISA kit (eBioscience), manifesting an MDD of $0.5 \mathrm{pg} / \mathrm{ml}$; for TNF- $\alpha$ : Quantikine HS Human TNF- $\alpha$ /TNFSF1A Immunoassay kit (R\&D Systems), manifesting an MDD of $0.106 \mathrm{pg} / \mathrm{ml}$; for IL- $1 \beta$ : Quantikine HS Human IL-1 $\beta / I L-1 F 2$ Immunoassay kit (R\&D Systems), manifesting an MDD of $0.057 \mathrm{pg} / \mathrm{ml}$; for IL-12: Human IL-12p70 High Sensitivity ELISA kit (eBioscience), manifesting an MDD of $0.1 \mathrm{pg} / \mathrm{ml}$.

The tests were performed as recommended by the manufacturers. Values of absorbance, depending on the estimated cytokine, were read at a wavelength of $A=450 \mathrm{~nm}$ or $490 \mathrm{~nm}$ using Reader 250 (bioMérieux). The results were obtained from standard curves.

\section{Data analysis}

In the comparative analysis of cytokine levels in the studied groups, the non-parametric test of Kruskal-Wallis with Dunn's test was employed.

In the analysis of Agr class systems in the examined strains of $S$. aureus, Student's $t$-test for fractions was employed, indicating a difference between two structural indices.

In every test, hypotheses were verified at the significance level of $p=0.05$.

\section{Results}

Levels of IFN- $\gamma$, IL-4, IL-10 and IL-17A cytokines, produced by lymphocytes $\mathrm{Th}$, detected in the sera of patient groups with $S$. aureus infections, manifesting by chronic suppurative dermatitis (group 1), chronic inflammation of the upper respiratory tract (group 2) and in healthy individuals are listed in Table 1. In group 1, the mean levels of IFN- $\gamma$ and IL-17A

Table 1 Levels of cytokines produced by lymphocytes Th (IFN- $\gamma$, IL4, IL-10, IL-17A) in the sera of patients with chronic suppurative dermatitis (group 1), with chronic inflammation in the upper respiratory tract (group 2) and in the control group (group 3)

\begin{tabular}{llll}
\hline Studied cytokine & \multicolumn{2}{l}{ Mean values in $\mathrm{pg} / \mathrm{ml} \pm \mathrm{SD}$} \\
\cline { 2 - 4 } & $\begin{array}{l}\text { Group 1, } \\
n=50\end{array}$ & $\begin{array}{l}\text { Group 2, } \\
n=40\end{array}$ & $\begin{array}{l}\text { Group } 3 \text { (control), } \\
n=25\end{array}$ \\
\hline IFN- $\gamma$ & $0.98 \pm 0.55^{*}$ & $0.87 \pm 0.51^{*}$ & $0.44 \pm 0.33$ \\
IL-4 & $0.29 \pm 0.14$ & $0.28 \pm 0.14$ & $0.24 \pm 0.12$ \\
IL-10 & $1.82 \pm 1.28$ & $1.72 \pm 1.28$ & $1.58 \pm 0.97$ \\
IL-17A & $4.93 \pm 1.54^{*}$ & $4.87 \pm 1.57^{*}$ & $1.93 \pm 0.83$
\end{tabular}

*Significant difference in cytokines levels between the patients and healthy subjects amounted to $0.98 \pm 0.55 \mathrm{pg} / \mathrm{ml}$ and $4.93 \pm 1.54 \mathrm{pg} / \mathrm{ml}$, respectively. In group 2 , the mean levels of IFN- $\gamma$ and IL-17A amounted to $0.87 \pm 0.51 \mathrm{pg} / \mathrm{ml}$ and $4.87 \pm 1.57 \mathrm{pg} / \mathrm{ml}$, respectively. The levels manifested no significant differences between patient groups 1 and 2, but they were significantly higher than those in group 3 (control). In turn, levels of IL-4 and IL-10 did not differ from those in the control group.

Levels of TNF- $\alpha$, IL-1 $\beta$ and IL-12, the cytokines produced by monocytes/macrophages, detected in the sera of patients (groups 1 and 2) and in healthy individuals (group 3) are presented in Table 2. Levels of TNF- $\alpha$ and IL-12 in both groups of the patients fitted the normal range. On the other hand, the mean levels of IL- $1 \beta$ in groups 1 and 2 amounted to $0.54 \pm 0.25 \mathrm{pg} / \mathrm{ml}$ and $0.50 \pm 0.25 \mathrm{pg} / \mathrm{ml}$, respectively. They manifested no significant differences between groups 1 and 2, but they were significantly higher than the values in the control group.

The diversification of individual Agr classes among the $S$. aureus strains isolated from the patients is presented in Table 3 . In groups 1 and 2, the proportion of S. aureus strains with Agr IV phenotype amounted to $58 \%$ and $65 \%$, respectively, and such a phenotype was significantly more frequent than the remaining phenotypes of Agr I-III. In parallel, no significant difference in the diversification of Agr classes could be demonstrated between groups 1 and $2(p>0.05)$.

In the analysis of cytokine response profiles in the context of the isolated strains of $S$. aureus in each of the patient groups (group 1 and group 2), respective subgroups of 1a and 2 a were distinguished, linked to the isolated $S$. aureus strains manifesting the phenotype of Agr I-III, and subgroups $1 \mathrm{~b}$ and $2 \mathrm{~b}$, linked to $S$. aureus strains manifesting Agr IV phenotype. Levels of IFN- $\gamma$, IL-4, IL-10 and IL-17A detected in the sera of patients in the subgroups $1 \mathrm{a}, 1 \mathrm{~b}, 2 \mathrm{a}$ and $2 \mathrm{~b}$ are presented in Table 4 . The obtained levels of the studied cytokines manifested no significant differences between subgroups $1 \mathrm{a}$ and $1 \mathrm{~b}$ or between subgroups $2 \mathrm{a}$ and $2 \mathrm{~b}$ $(p>0.05)$. Levels of TNF- $\alpha$, IL-1 $\beta$ and IL-12, detected in the sera of patients in subgroups $1 \mathrm{a}, 1 \mathrm{~b}, 2 \mathrm{a}$ and $2 \mathrm{~b}$ are

Table 2 Cytokines levels produced by monocytes/macrophages (TNF- $\alpha$, IL-1 $\beta$, IL-12) in the sera of patients with chronic suppurative dermatitis (group 1), with chronic inflammation in the upper respiratory tract (group 2) and in the control group (group 3)

\begin{tabular}{llll}
\hline Studied cytokine & \multicolumn{2}{l}{ Mean values in $\mathrm{pg} / \mathrm{ml} \pm \mathrm{SD}$} \\
\cline { 2 - 4 } & $\begin{array}{l}\text { Group 1, } \\
n=50\end{array}$ & $\begin{array}{l}\text { Group 2, } \\
n=40\end{array}$ & $\begin{array}{l}\text { Group 3 (control), } \\
n=25\end{array}$ \\
\hline TNF- $\alpha$ & $0.77 \pm 0.39$ & $0.74 \pm 0.3$ & $0.61 \pm 0.36$ \\
IL-1 $\beta$ & $0.54 \pm 0.25^{*}$ & $0.50 \pm 0.25^{*}$ & $0.26 \pm 0.14$ \\
IL-12 & $0.45 \pm 0.35$ & $0.42 \pm 0.33$ & $0.38 \pm 0.31$
\end{tabular}

* Significant difference in cytokines levels between the patients and healthy subjects 
Table 3 Diversification of Agr system classes among $S$. aureus isolates obtained from the examined patients of groups 1 and 2

\begin{tabular}{llll}
\hline Agr classes & $\begin{array}{l}\text { Group 1, } \\
n=50\end{array}$ & $\begin{array}{l}\text { Group 2, } \\
n=40\end{array}$ & $\begin{array}{l}p \text {-value for difference } \\
\text { between groups 1 and 2 }\end{array}$ \\
\hline I & $12(24 \%)$ & $8(20 \%)$ & $p=0.6513$ \\
II & $5(10 \%)$ & $3(7.5 \%)$ & $p=0.6798$ \\
III & $4(8 \%)$ & $3(7.5 \%)$ & $p=0.8588$ \\
IV & $29(58 \%)^{*}$ & $26(65 \%)^{*}$ & $p=0.5003$ \\
\hline
\end{tabular}

*Difference in the frequency of manifestation, as compared to Agr classes I, II and III, at the level of $p<0.001$

presented in Table 5. Levels of the examined cytokines manifested no significant differences between subgroups $1 \mathrm{a}$ and $1 \mathrm{~b}$ or between subgroups $2 \mathrm{a}$ and $2 \mathrm{~b}(p>0.05)$.

\section{Discussion}

This study analysed the levels of the circulating cytokines secreted by subpopulations of Th lymphocytes and monocytes/macrophages in patients with $S$. aureus chronic infections, and diversified classes of Agr systems among the isolated clinical strains of $S$. aureus. IFN- $\gamma$, mainly produced by activated Th1 lymphocytes, provides an optimal help for cellular immunity, including pronounced stimulation of monocytes/macrophages $[13,14]$. On the other hand, IL-4 and IL-10, produced mainly by activated Th2 lymphocytes, provide optimal help for humoral immune response, while they suppress the reactions controlled by Th1 cells and, in parallel, they diminish pro-inflammatory functions of monocytes/macrophages $[13,15]$. IL-17, in turn, produced mainly by activated Th17 lymphocytes, represents a proinflammatory cytokine, playing a significant role in the induction of local or systemic immune reactions, by firstly recruiting neutrophils against infectious agents [16, 17]. Classical pro-inflammatory cytokines, TNF- $\alpha$, IL-1 $\beta$ and IL-12, produced mainly by activated monocytes/macrophages, demonstrate a broad immunostimulatory activity and, in parallel, they cooperate with IL-17 in the induction of inflammatory host reactions [18].

In this study, elevated levels of IFN- $\gamma$ and IL-17A were documented, but IL-4 and IL-10 levels were within the normal ranges in the sera of patients with $S$. aureus infections, manifested by chronic suppurative dermatitis or chronic inflammation in the upper respiratory tract. The results point to a continuous response of Th1/Th17 lymphocytes, accompanied by a failed induction of Th2 cells in the course staphylococcal chronic infection. In part, the conclusion corroborates the earlier studies of Breuer et al. [19] and, recently, those of Niebuhr et al. [20], who showed that $\alpha$ toxin, the 33-kDa cytolysin secreted by $S$. aureus, induced the release of IFN- $\gamma$ and IL-17 in human $\mathrm{CD}^{+} \mathrm{T}$ cells. Moreover, staphylococcal peptidoglycan (PGN), with mediation of dendritic cells (DCs), was noted to induce Th1/ Th17 response [21]. In addition, in the most common inflammatory human skin diseases, atopic dermatitis [22] and psoriasis [23], an increase was noted in circulating Th1 and Th17 cells. Apart from the distinct lines of Th1 and Th17 lymphocytes, also the mixed Th17/Th1 cell type is distinguished, which combines the pro-inflammatory potential of Th17 and Th1 cells, being characterised by the production of both IFN- $\gamma$ and IL-17 [24]. These Th17/Th1 cells manifest a stable coexpression of transcription factors T-bet and ROR $\gamma t$, most probably originating from Th17 lymphocytes, and account for a rare population of circulating cells, representing only $0.05-0.11 \%$ of $\mathrm{CD}^{+} \mathrm{T}$ cells in human healthy blood $[25,26]$. In the context of the data, the increased levels of IFN- $\gamma$ and IL-17A detected by us in the sera of patients may reflect a preferential induction and accumulation of Th17/Th1 cells in the foci of dermatitis or upper respiratory mucositis induced by $S$. aureus infection. Secretory activity of the cells is probably involved in the development of chronic inflammatory processes, linked to $S$. aureus infection. This potential has been demonstrated by in vitro studies of Boniface et al. [27], showing that, in contrast to human Th1 or Th17 lymphocytes, Th17/Th1 cells manifest a greater propensity to induce inflammation on epithelial cells. On the other hand, Cho et al. [28]
Table 4 Cytokine levels produced by lymphocytes Th (IFN$\gamma$, IL-4, IL-10, IL-17A) in the sera of patients in subgroups 1a and 2a, linked to $S$. aureus isolates manifesting Agr I-III phenotypes, and subgroups $1 \mathrm{~b}$ and $2 \mathrm{~b}$, linked to $S$. aureus strains manifesting Agr IV phenotype

\begin{tabular}{|c|c|c|c|c|}
\hline \multirow{3}{*}{$\begin{array}{l}\text { Studied } \\
\text { cytokine }\end{array}$} & \multicolumn{4}{|c|}{ Mean values in $\mathrm{pg} / \mathrm{ml} \pm \mathrm{SD}$} \\
\hline & \multicolumn{2}{|l|}{ Group $1, n=50$} & \multicolumn{2}{|l|}{ Group 2, $n=40$} \\
\hline & $\begin{array}{l}\text { Subgroup 1a: Agr I- } \\
\text { III, } n=21\end{array}$ & $\begin{array}{l}\text { Subgroup 1b: Agr } \\
\text { IV, } n=29\end{array}$ & $\begin{array}{l}\text { Subgroup 2a: Agr I- } \\
\text { III, } n=14\end{array}$ & $\begin{array}{l}\text { Subgroup 2b: Agr } \\
\text { IV, } n=26\end{array}$ \\
\hline IFN- $\gamma$ & $1.01 \pm 0.59$ & $0.96 \pm 0.52$ & $0.81 \pm 0.49$ & $0.91 \pm 0.52$ \\
\hline IL-4 & $0.38 \pm 0.16$ & $0.32 \pm 0.14$ & $0.31 \pm 0.14$ & $0.33 \pm 0.15$ \\
\hline IL-10 & $1.84 \pm 1.17$ & $1.81 \pm 1.37$ & $1.79 \pm 1.27$ & $1.68 \pm 1.31$ \\
\hline IL-17A & $5.1 \pm 1.66$ & $4.81 \pm 1.47$ & $4.98 \pm 1.75$ & $4.82 \pm 1.5$ \\
\hline
\end{tabular}


Table 5 Cytokines levels produced by monocytes/macrophages (TNF- $\alpha$, IL-1 $\beta$, IL-12) in the sera of patients in subgroups 1 a and 2a, linked to $S$. aureus isolates manifesting Agr I-III phenotypes, and subgroups $1 \mathrm{~b}$ and $2 \mathrm{~b}$, linked to $S$. aureus strains manifesting Agr IV phenotype

\begin{tabular}{llllll}
\hline $\begin{array}{l}\text { Studied } \\
\text { cytokine }\end{array}$ & \multicolumn{2}{l}{ Mean values in $\mathrm{pg} / \mathrm{ml} \pm \mathrm{SD}$} & & \\
\cline { 2 - 3 } & \multicolumn{2}{l}{ Group 1, $n=50$} & & Group 2, $n=40$ & \\
\cline { 2 - 3 } & $\begin{array}{l}\text { Subgroup 1a: Agr I- } \\
\text { III, } n=21\end{array}$ & $\begin{array}{l}\text { Subgroup 1b: Agr } \\
\text { IV, } n=29\end{array}$ & & $\begin{array}{l}\text { Subgroup 2a: Agr I- } \\
\text { III, } n=14\end{array}$ & Subgroup 2b: Agr \\
& $0.68 \pm 0.36$ & $0.84 \pm 0.4$ & $0.82 \pm 0.36$ & IV, $n=26$ \\
\hline TNF- $\alpha$ & $0.48 \pm 0.26$ & $0.58 \pm 0.24$ & $0.47 \pm 0.26$ & $0.7 \pm 0.26$ \\
IL-1 $\beta$ & $0.42 \pm 0.36$ & $0.48 \pm 0.35$ & $0.37 \pm 0.34$ & $0.52 \pm 0.25$ \\
IL-12 & & &
\end{tabular}

demonstrated, using a mouse model, that IL-17, priming neutrophil recruitment, is ultimately required for host defence against $S$. aureus skin infections. The 2.5-fold increase in circulating IL-17A detected by us in patients is apparently insufficient for the induction of an adequate response against $S$. aureus infection but, together with the released IFN- $\gamma$, it may promote the development of a chronic inflammatory process. In our study, we have demonstrated a doubled increase in levels of circulating IFN- $\gamma$, which, however, was not accompanied by increased levels of circulating TNF- $\alpha$ and IL12. In turn, the augmented level of circulating IL-1 $\beta$ detected by us might have resulted from secretion of the cytokine by IFN- $\gamma$ stimulated cells of vascular endothelium [29]. Thus, the demonstrated increased levels of IFN- $\gamma$ are insufficient for an effective induction of secretory function in monocytes/macrophages. In parallel, studies of Minegishi et al. [30] documented an immunological role of anti-staphylococcal factors, including neutrophil-recruiting chemokines and antimicrobial peptides, the secretion of which by human keratinocytes and bronchial epithelial cells is deeply dependent on the synergistic action of IL-17 and the combination of other pro-inflammatory cytokines (TNF- $\alpha+$ IL- $1 \beta+$ IFN- $\gamma$ ). In that context, it seems probable that the development of infection with $S$. aureus in the studied patients was linked to an insufficient stimulation of epithelial cell secretory function in the skin and upper respiratory tract due to impoverished cytokine response of monocytes/macrophages. In parallel, the preferentially pathogen-induced lymphocytes Th17/Th1 may be responsible for the promotion of chronic dermatitis or chronic respiratory tract infection. Quite possibly, $S$. aureus strains with deficient production of delta-toxin are responsible for the preferential induction, as it has seemed to be indicated by recent studies of Gagnaire et al. [31]. In turn, Zielinski et al. [32] have found that, due to a continuous stimulation by a pathogen, Th17 cells may acquire the ability to produce IL-10. In parallel, the above-quoted authors have shown that the phenomenon is inhibited by IL-1 $\beta$. The data correspond to the increased levels of IL- $1 \beta$ demonstrated by us in this study.

Among the isolated strains of $S$. aureus, originating either from patients with suppurative infections or from patients with upper respiratory tract inflammation, we have demonstrated a significant dominance of class IV Agr, while diversification of the remaining Agr classes demonstrated no significant differences. The dominance of class IV Agr among strains isolated from Polish patients, mainly patients with suppurative infections, has been described previously [33]. Moreover, strains with class IV Agr were found to be rare among healthy carriers of $S$. aureus $[33,34]$. A relationship was also described between strains of $S$. aureus belonging to class IV Agr and the production of epidermolytic toxins (exfoliatins, ETs) and the phylogenetic group AF1, in contrast to AF2, which corresponded to strains of class I and II Agr, and AF3, which corresponded to strains of class III Agr [10, 35]. In this study, however, in none of the patients could generalised or localised forms of staphylococcal scalded skin syndrome (SSSS) be diagnosed, induced by ETs [36]. Thus, the clinical data indicate that the strains isolated from $S$. aureus patients produced no ETs. Moreover, the sera of studied patients demonstrated no extremely high levels of IFN- $\gamma$, IL-17A or IL-1 $\beta$ and concentrations of TNF- $\alpha$ remained within the normal range. It is already well recognised that the toxins released by $S$. aureus, including enterotoxins, toxic shock syndrome toxin-1 and ETs, exert activity of superantigens on the host immune system [36, 37]. Such an activity results in extremely high levels of circulating various cytokines, including TNF- $\alpha[37,38]$.

Upon analysis of the studied profile of cytokine response, we have demonstrated no qualitative or quantitative differences between subgroups of patients linked to infections with $S$. aureus strains belonging to class IV Agr and patients infected with strains belonging to the remaining classes I-III Agr. The data allow to suggest that the antigenic profile of virulence factors released by $S$. aureus does not depend on the Agr class of the pathogen. The suggestion corroborates the earlier studies of Jarraud et al. [10], pointing to an absence of a direct role of the Agr class in the type of human disease induced by $S$. aureus. Nevertheless, in contrast to healthy carriers of $S$. aureus, strains isolated from patients are dominated by those belonging to class IV Agr. Thus, it seems possible that this Agr phenotype is particularly linked to the activation of virulence factors, which preconditions its preferential relationship with the pathogenicity of $S$. aureus.

Thus, our results demonstrate that patients with $S$. aureus infections, manifested by chronic suppurative dermatitis or 
chronic inflammation of the upper respiratory tract, develop a Th17/Th1 cytokine response, not accompanied by a sufficient pro-inflammatory response of monocytes/macrophages. Therefore, it is possible that lymphocytes Th17/ Th1 are responsible for the promotion of a chronic inflammatory process induced by $S$. aureus. In parallel, it was demonstrated that cytokine response does not differ between subgroups of patients infected with $S$. aureus strains belonging to class IV Agr and those infected with strains belonging to the remaining classes I-III Agr. In patients, the strains of class IV Agr prevailed, which points to a preferential relationship between the class and pathogenicity of $S$. aureus.

Acknowledgments This work was supported by the Polish Ministry of Science and Higher Education, Poland (grant no. N N401 004637).

\section{Conflict of interest Nothing to declare.}

Open Access This article is distributed under the terms of the Creative Commons Attribution License which permits any use, distribution, and reproduction in any medium, provided the original author(s) and the source are credited.

\section{References}

1. Espersen F, Hedström SA (1984) Recurrent staphylococcal furunculosis: antibody response against Staphylococcus aureus. Scand J Infect Dis 16:413-414

2. Proctor RA, Balwit JM, Vesga O (1994) Variant subpopulations of Staphylococcus aureus as cause of persistent and recurrent infections. Infect Agents Dis 3:302-312

3. Lowy FD (1998) Staphylococcus aureus infections. N Engl J Med 339:520-532

4. Clement S, Vaudaux P, Francois P et al (2005) Evidence of an intracellular reservoir in the nasal mucosa of patients with recurrent Staphylococcus aureus rhinosinusitis. J Infect Dis 192:10231028

5. Medzhitov R (2007) Recognition of microorganisms and activation of the immune response. Nature 449:819-826

6. Lindsay JA, Holden MT (2004) Staphylococcus aureus: superbug, super genome? Trends Microbiol 12:378-385

7. Foster TJ (2005) Immune evasion by staphylococci. Nat Rev Microbiol 3:948-958

8. Ji G, Beavis R, Novick RP (1997) Bacterial interference caused by autoinducing peptide variants. Science 276:2027-2030

9. Novick RP (2003) Autoinduction and signal transduction in the regulation of staphylococcal virulence. Mol Microbiol 48:14291449

10. Jarraud S, Mougel C, Thioulouse J et al (2002) Relationships between Staphylococcus aureus genetic background, virulence factors, agr groups (alleles), and human disease. Infect Immun 70:631-641

11. Shopsin B, Mathema B, Alcabes P et al (2003) Prevalence of $a g r$ specificity groups among Staphylococcus aureus strains colonizing children and their guardians. J Clin Microbiol 41:456-459

12. Campoccia D, Baldassarri L, Pirini V et al (2008) Molecular epidemiology of Staphylococcus aureus from implant orthopaedic infections: ribotypes, agr polymorphism, leukocidal toxins and antibiotic resistance. Biomaterials 29:4108-4116
13. Mosmann TR, Sad S (1996) The expanding universe of T-cell subsets: Th1, Th2 and more. Immunol Today 17:138-146

14. Moser M, Murphy KM (2000) Dendritic cell regulation of $\mathrm{T}_{\mathrm{H}} 1$ $\mathrm{T}_{\mathrm{H}} 2$ development. Nat Immunol 1:199-205

15. Mege J-L, Meghari S, Honstettre A et al (2006) The two faces of interleukin 10 in human infectious diseases. Lancet Infect Dis 6:557-569

16. Reiner SL (2007) Development in motion: helper T cells at work. Cell 129:33-36

17. Tesmer LA, Lundy SK, Sarkar S, Fox DA (2008) Th17 cells in human disease. Immunol Rev 223:87-113

18. Medzhitov R, Janeway CA Jr (1997) Innate immunity: impact on the adaptive immune response. Curr Opin Immunol 9:4-9

19. Breuer K, Wittmann M, Kempe K et al (2005) Alpha-toxin is produced by skin colonizing Staphylococcus aureus and induces a T helper type 1 response in atopic dermatitis. Clin Exp Allergy 35:1088-1095

20. Niebuhr M, Gathmann M, Scharonow H et al (2011) Staphylococcal alpha-toxin is a strong inducer of interleukin-17 in humans. Infect Immun 79:1615-1622

21. Frodermann V, Chau TA, Sayedyahossein S et al (2011) A modulatory interleukin-10 response to staphylococcal peptidoglycan prevents Th1/Th17 adaptive immunity to Staphylococcus aureus. J Infect Dis 204:253-262

22. Koga C, Kabashima K, Shiraishi N et al (2008) Possible pathogenic role of Th17 cells for atopic dermatitis. J Invest Dermatol 128:2625-2630

23. Lowes MA, Kikuchi T, Fuentes-Duculan J et al (2008) Psoriasis vulgaris lesions contain discrete populations of Th1 and Th17 T cells. J Invest Dermatol 128:1207-1211

24. Acosta-Rodriguez EV, Rivino L, Geginat J et al (2007) Surface phenotype and antigenic specificity of human interleukin 17producing $\mathrm{T}$ helper memory cells. Nat Immunol 8:639-646

25. Lexberg MH, Taubner A, Albrecht I et al (2010) IFN- $\gamma$ and IL-12 synergize to convert in vivo generated Th17 into Th1/Th17 cells. Eur J Immunol 40:3017-3027

26. Kagami S, Rizzo HL, Lee JJ et al (2010) Circulating Th17, Th22, and Th1 cells are increased in psoriasis. J Invest Dermatol 130:1373-1383

27. Boniface K, Blumenschein WM, Brovont-Porth K et al (2010) Human Th17 cells comprise heterogeneous subsets including IFN- $\gamma$-producing cells with distinct properties from the Th1 lineage. J Immunol 185:679-687

28. Cho JS, Pietras EM, Garcia NC et al (2010) IL-17 is essential for host defense against cutaneous Staphylococcus aureus infection in mice. J Clin Invest 120:1762-1773

29. Krishnaswamy G, Kelley J, Yerra L et al (1999) Human endothelium as a source of multifunctional cytokines: molecular regulation and possible role in human disease. J Interferon Cytokine Res 19:91-104

30. Minegishi Y, Saito M, Nagasawa M et al (2009) Molecular explanation for the contradiction between systemic Th17 defect and localized bacterial infection in hyper-IgE syndrome. J Exp Med 206:1291-1301

31. Gagnaire J, Dauwalder O, Boisset S et al (2012) Lack of Staphylococcus aureus delta-toxin production as detected by whole cell MALDI-TOF MS in routine practice is associated with chronicity of infection. Clin Microbiol Infect 3 (Suppl):694, Abstract P2355

32. Zielinski CE, Mele F, Aschenbrenner D et al (2012) Pathogen-induced human Th17 cells produce IFN- $\gamma$ or IL-10 and are regulated by IL-1 $\beta$. Nature 484:514-518. doi:10.1038/nature10957

33. Garbacz K, Piechowicz L, Wiśniewska K et al (2009) Diversification of agr locus among Staphylococcus aureus isolated from 
carriers and from hospital patients with infection syndromes. Med Dośw Mikrobiol 61:5-9

34. Collery MM, Smyth DS, Twohig JM et al (2008) Molecular typing of nasal carriage isolates of Staphylococcus aureus from an Irish university student population based on toxin gene PCR, agr locus types and multiple locus, variable number tandem repeat analysis. J Med Microbiol 57:348-358

35. Jarraud S, Lyon GJ, Figueiredo AM et al (2000) Exfoliatinproducing strains define a fourth agr specificity group in Staphylococcus aureus. J Bacteriol 182:6517-6522
36. Ladhani S, Joannou CL, Lochrie DP et al (1999) Clinical, microbial, and biochemical aspects of the exfoliative toxins causing staphylococcal scalded-skin syndrome. Clin Microbiol Rev 12:224-242

37. Müller-Alouf H, Carnoy C, Simonet M et al (2001) Superantigen bacterial toxins: state of the art. Toxicon 39:1691-1701

38. Mele T, Madrenas J (2010) TLR2 signalling: at the crossroads of commensalism, invasive infections and toxic shock syndrome by Staphylococcus aureus. Int J Biochem Cell Biol 42:1066-1071 